\title{
EL TEJIDO Y LA SIMBOLOGÍA DE LA CULTURA DE LOS PASTOS EN LA INDUMENTARIA REGIONAL
}

\section{Entorno Cuerpo}

Jacqueline Marcela Rosero Ortega

yakimar2306@gmail.com

Camila Stefhany Urbina Figueroa

camifgr13@gmail.com

Universidad de Nariño.

Pasto, Nariño. 


\section{Resumen}

EI proyecto de investigación tuvo como objetivo resaltar una cultura de gran importancia -dentro del Departamento de Nariño; para esto se buscó información y se profundizó en conceptos enmarcados dentro del ámbito cultural, tomando como caso a la comunidad de los Pastos y su cultura. Con el propósito de resaltar su simbología y tradición ancestral en el Municipio de Cumbal, se orientó hacia el arte de tejer, mediante la fusión de técnicas de costura y uso de diferentes materiales, para generar productos diferentes que llamen la atención de la población y, sobre todo, de la juventud del Municipio de Pasto; con la finalidad de posicionar una marca que represente a la cultura en mención. Como metodología se acogió el enfoque cualitativo, método crítico social y tipo de investigación acción participación. Se basó en el análisis de la parte simbólica y el manejo de los procedimientos de diseño implícitos en el objeto estético; así, se recurrió a la semiología de las artes visuales. El estudio se desarrolló en cuatro etapas: acercamiento, ideación, experimentación y prototipado. La muestra estuvo conformada por las tejedoras de Cumbal, con edades entre 25 a 50 años y jóvenes de la ciudad de Pasto de 18 a 25 años. Como conclusión, el trabajo se torna valioso, porque cada tejido es elaborado a mano, le depositan su tiempo, esfuerzo y dedicación, pues el tejer no es algo sencillo, requiere de varios procesos, de imaginación, creatividad y paciencia para darle vida a cada diseño.

\section{Problema}

\section{- Descripción del problema}

La historia de la humanidad ha estado marcada por múltiples aspectos que caracterizan diferentes culturas y diferentes épocas: la evolución del pensamiento, su desarrollo económico o sus características culturales, representadas en gastronomía, arte, religión, entre otros, han sido elementos que se han convertido a lo largo de los tiempos en iconos de identidad y preservación.

En el Departamento de Nariño existe una de esas culturas milenarias, que aún conserva el legado de sus ancestros. Es la cultura de los Pastos, cuya herencia se manifiesta en varios aspectos; pero, para el objetivo de la investigación, se trabajó con el arte de tejer, habilidad que fue desarrollada por la necesidad de vestir y proteger el cuerpo de las condiciones climáticas y que se fue perfeccionando a través del tiempo, hasta llegar a la implementación de diferentes técnicas, como el tejido en guanga, propio de esta cultura, y el punto crochet que, a pesar de su origen diverso, ha sido adoptado por ella. Ambas cobran importancia, porque diferentes simbologías se encuentran plasmadas en los tejidos que conservan el legado cultural que revive la memoria de los antepasados.

Como sucede en la mayoría de los casos, la tradición se trasmite de generación en generación a través del tiempo, y las comunidades indígenas del Municipio de Cumbal en Nariño, no son la excepción. Un gran número de mujeres tejedoras han logrado mantener 
vivos y vigentes estos saberes ancestrales, anteponiéndose a la progresiva pérdida de identidad cultural, que les permite a su vez reivindicar la existencia, identidad e importancia de la Cultura de los Pastos para la región.

Esta necesidad de reivindicación nace de la observación del entorno, que las nuevas generaciones desconocen o que poco les importa conocer sus raíces, por ejemplo, los jóvenes que habitan ciudades como Pasto. Se ven así invadidos por tendencias ajenas a su entorno inmediato, las formas de vestir reflejan cada vez más la influencia de otras culturas, dejando atrás las tradiciones ancestrales que han marcado su presente. Es por esta razón que el objetivo de esta investigación se centró en diseñar una línea de ropa juvenil que resaltara la cultura de los Pastos, a través de símbolos, texturas y colores característicos plasmados en el tejido, para generar prendas atractivas y modernas con factores distintivos y únicos que llamen la atención de los jóvenes; además de diseñar una marca propia que refleje la esencia de la cultura investigada.

\section{- Formulación del problema}

¿Cómo resaltar la técnica del tejido y la simbología de la Cultura de los Pastos, para generar un reconocimiento por parte de los jóvenes ciudadanos de Pasto?

\section{- Justificación}

En la actualidad se vive en un mundo que cambia constantemente, teniendo en cuenta que una marca o producto puede expandirse progresivamente, imponiéndose en diferentes lugares alrededor del mundo. Este fenómeno se ve reflejado en la indumentaria que, por su amplia gama de tendencias, presenta siempre algo innovador, captando la atención de los consumidores. Por lo tanto, es importante para esta investigación comprender el comportamiento de los jóvenes ciudadanos de Pasto hacia esta tendencia; y lograr generar una línea de ropa que sea atractiva para la población juvenil.

Remontándose a una cultura ancestral indígena de gran importancia para los nariñenses, como es la cultura de los Pastos, pueblo que ha habitado diferentes zonas de la región, dejando un legado rico visualmente y plasmando en diversos objetos su gráfica; esa impronta será la inspiración para generar una nueva propuesta que permita resaltar esta cultura a partir de su simbología y la técnica del tejido.

La importancia de abordar esta investigación desde el ámbito del Diseño Gráfico, radica en que esta disciplina brinda varias herramientas que permiten desarrollar un proceso de trabajo colaborativo con las tejedoras pertenecientes a la comunidad de los Pastos, en el Municipio de Cumbal, y los jóvenes ciudadanos del Municipio de Pasto, para producir, así, una línea de ropa con diseños basados en la grafía de esta cultura. A su vez, se creó una marca que representa y simplifica los símbolos de la misma, reforzando la identidad y tradición en el territorio nariñense, para así posicionar en la región, más que un estilo de indumentaria, un sentido de pertenencia con respecto a la cultura de los Pastos. 


\section{Marco teórico}

\section{- La semiótica del diseño andino}

La semiótica del diseño hace referencia a una disciplina que define los aspectos simbólicos que se utilizan dentro de los procesos constructivos del diseño; estudia, también, las formas del arte permitiendo asociarlas a un contexto cultural al cual pertenecen. De esta manera, pone en relación la arqueología y la antropología, que aportan la información y una fuente teórica acerca de la ubicación del objeto estético; esto hace parte de un proceso de desarrollo general y específico.

La metodología que se utilizó, se basa en el análisis del conocimiento de la parte simbólica y el manejo de los procedimientos de diseño implícitos en el objeto estético. Para llevarlo a cabo se recurrió a la semiología de las artes visuales; según Uribe (2004):

Trata sobre el estudio comparativo del origen, formación interpretación de los símbolos y los lenguajes, estableciendo las leyes de su sintaxis y su semántica; la topología que estudia las propiedades geométricas cualitativas del espacio, al margen de su medida o significación concreta, pero que permite comparar los principios geométricos de la forma con los valores culturales de su significado; y la estética que determina los valores conceptuales, compositivos y estilísticos del objeto artístico en relación a las condicionantes de su creación.

El objetivo de la semiótica del Diseño Andino, es estudiar las expresiones del arte precolombino, sobre todo en su aspecto conceptual, por lo cual se estudiaron tres aspectos principales: el lenguaje, la composición y el simbolismo.

\section{- Los quillacingas y los pastos coaiqueres de nariño}

En Nariño existen dos grupos de indígenas que no fueron totalmente asimilados por la cultura europea, los Quillacingas y los Pastos o Coaiqueros. Durante la época de la conquista, ellos se distinguieron por sus lenguas, que en la actualidad se encuentran extintas, pero que pertenecen al grupo lingüístico Chibcha. Los lingüistas distinguen en Nariño, a la familia Coche o Kamsá, que hablaba la lengua Quillacinga, y la familia Tucano, que hablaba la lengua Pasto o Cuaiquer. Se define a estos grupos como:

Señores de una tierra maravillosa, de grandiosas montañas, de volcanes empenachados y de profundas cañadas por donde corren precipitados los ríos y las quebradas, los indios de Nariño se apegaron al espectáculo de su naturaleza y a las creencias relativas a tanta grandeza geológica, y mantuvieron su personalidad étnica a través del terremoto de la conquista española. (Alcaldía del Municipio de Pasto, 2011) 


\section{- Los Pastos o Coaiqueres}

El área habitada por estos indios cae al oriente del departamento de Nariño, desde Guáitara, su límite con Quillacingas, hasta la cálida costa pacífica y desde el límite norte con el departamento del Cauca hasta el Mira y San Juan, limite internacional colomboecuatoriano. (Alcaldía del Municipio de Pasto, 2011)

Los Pastos o Coaiqueres llevan una vida nómada, por lo cual prefieren la selva como su hábitat y algunos de ellos han establecido pequeños pueblos. Su estilo de vida es poco común, no utilizan camas o algún tipo de soporte en donde pasar sus noches; por el contrario, sólo se acomodan en el suelo y apenas utilizan algún tipo de techo para poder protegerse del clima. No son hospitalarios, aun si se trata de algún familiar; en ocasiones, cortan su cabello a la altura de su nuca, llevan un pedazo de tela larga sin adornos, como falda hasta la mitad de las rodillas. Para sus fiestas o rituales, algunos de ellos pintan su frente, mejillas y nariz con bija, un colorante de origen natural.

\section{- La Espiral}

Para la cultura de los Pastos, la Espiral, también conocida como Churo Cósmico, representa el movimiento de adentro hacia afuera, que simboliza el pensamiento andino de la cultura. Es como un pensamiento religioso, ya que los lugares en donde se encontraba grabado este símbolo, fueron sitios en donde se realizaron ceremonias de curación o culto, donde se hacían ofrendas al agua, al fuego o a la luna; puesto que en el arte de los Pastos y Quillancingas, la espiral representa el principio de la vida, el tiempo infinito, el agua y la fertilidad.

\section{- La Estrella de ocho puntas}

La Estrella de ocho puntas, o Sol de los Pastos, es otro de los símbolos más representativos para los Pastos y Quillacingas. Se encuentra, frecuentemente, en el arte rupestre y la alfarería. Para algunos autores, este símbolo también representa un calendario solar que marcaba los solsticios y equinoccios. El Sol de los Pastos indica caminos, estaciones y suele encontrarse pintado sobre piedras o platos de barro cocido; pero éste siempre se encuentra rodeado de grupos humanos o de animales y viviendas. El diseño de este símbolo se ha mantenido en la artesanía en Nariño y Ecuador; en la actualidad es utilizada comúnmente en tejidos.

\section{- El Cusillo}

La imagen del mono, o Cusillo, es otro símbolo principal dentro de la cultura de los Pastos y Quillancingas. Su tamaño y posición varía, y la forma de cola es enroscada. Se encuentra representado en pequeñas ocarinas o copas que se utilizan para ceremonias; es por eso que el Cusillo se encuentra en el arte rupestre y la alfarería. 


\section{- Municipio de Cumbal}

En cuanto a los antecedentes étnicos de los Pastos, se encuentran diferentes versiones. Según José Rámazo Gonzales (citado en Alcaldía del Municipio de Cumbal, 2009), en su estudio: El Ecuador en la normal América Prehispánica, habla de los Pastos como:

Una "raza extraña", hace alusión a los Quillacingas, Sibundoyes, Barbacoas al Norte y a los Imbaburas, Caraquiscayapa colorados en el Sur, todos estos pertenecientes al ramo de los Chibchas; los Pastos se encontraban en el medio rompiendo esta Unidad de Pueblo. En la misma obra dice que los Pastos no deben ser confundidos con los Quillacingas, de origen Chibcha y con lenguas diferentes.

La lengua Pasto se conservó hasta medio siglo después de la conquista, manteniéndose como una lengua distinta y difícil de aprender. Según el autor citado, la raza de los Pastos no pertenece al grupo Chibcha sino, por el contrario, es de origen amazónico. Es posible afirmar que existe un cierto mestizaje gracias a las evidencias que se han encontrado dentro de las culturas Maya, Inca y las de los Caribes, para generar, así, una fuerte influencia cultural dentro de los Pastos.

La invasión incaica presidida por la llegada de los españoles acelero la devastación de los pueblos Pastos; de esta forma los ritos, ceremonias, el vestido, la lengua, los sistemas religiosos, la cultura general de esta etnia fue desapareciendo paulatinamente quedando muy poco o ningún vestigio de sus templos, ni memoria de sus casas de recogimiento. (Alcaldía del Municipio de Cumbal, 2009)

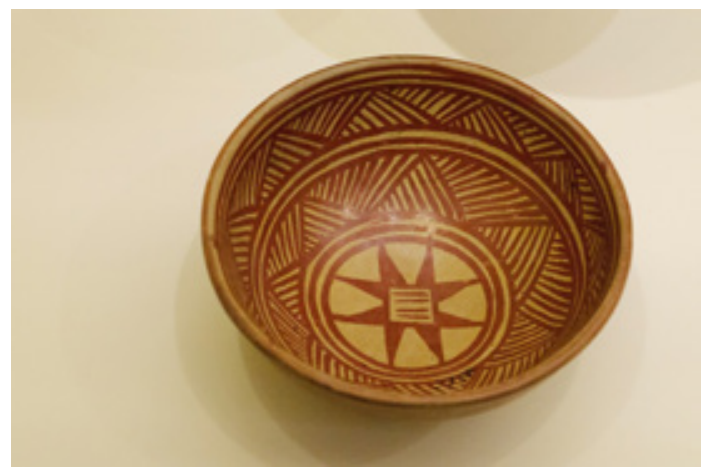

Figura 1. Vasija Sol de los Pastos

Fuente: Fotografía de las autoras.

\section{- El tejido}

En Colombia se han encontrado vestigios de tejidos en diferentes regiones, la principal zona textil se encuentra en el sur de Nariño, en tierras que han sido habitadas por los Pastos. Sin embargo, los textiles que se han podido conservar son pocos, debido a factores que han impedido su conservación. 
Los textiles que se han logrado conservar en Colombia han estado en ambientes secos y de temperatura cálida, en tumbas dentro de cuevas o abrigos rocosos. En la mayoría de los casos, las tumbas se encuentran en la tierra y a esto se debe que contemos con muy pocos vestigios textiles. (Tavera \& Urbina, 1994)

Para el Departamento de Nariño, las labores artesanales son de gran importancia. Una de ellas es el tejido, actividad que se ha caracterizado por ser heredada y mantenerse vigente, alcanzando altos niveles de calidad. Es importante resaltar que esta actividad, por mucho tiempo, ha estado relacionada con las mujeres, debido a que son ellas las que poseen el conocimiento, la habilidad y la destreza para desarrollarla. A su vez, el tejido cumple un papel fundamental, ya que en él se conserva el legado cultural que revive la historia de los antepasados; al respecto Tavera y Urbina (1994) comentan: "Los textiles están estrechamente ligados a los aspectos socioculturales, religiosos, económicos y de expresión artística. Su estudio enriquece notablemente el conocimiento que se tiene de nuestros antepasados precolombinos y sobre su relación con otras culturas americanas".

El tejido tiene gran importancia, puesto que constituyó uno de los lenguajes por medio de los cuales los pueblos se expresaban, además de fundamentarse en las necesidades humanas como cubrir y abrigar el cuerpo, conformándose, también, como un factor de identidad: "Mostraba el rango o la clase social de quien lo utilizaba, se ofrecía como premio, como forma de atributo y ofrenda y como elemento importante en el trueque con otros grupos". (Tavera \& Urbina, 1994)

Entre los pueblos andinos se alcanzó un gran desarrollo en cuanto a la producción textil, toda vez que las técnicas utilizadas eran destacables por la destreza empleada, junto con el sistema simbólico; Pantoja (2009) dice al respecto:

En la indumentaria de la cultura Pastos se puede entender la belleza artística a través de la simbología andina con diseños de códigos, signos que representan toda la grafía del cosmos, además son estructuras que dan a conocer la escritura con la que se comunicaron las comunidades ancestrales, como huella imborrable del pensamiento antepasado. Son rescatables las técnicas utilizadas en la cultura andina, tradición que ha servido para mantener y conservar las destrezas ancestrales, el tejido trae significado y refleja el pensamiento como algo que está vivo en la memoria de los pueblos.

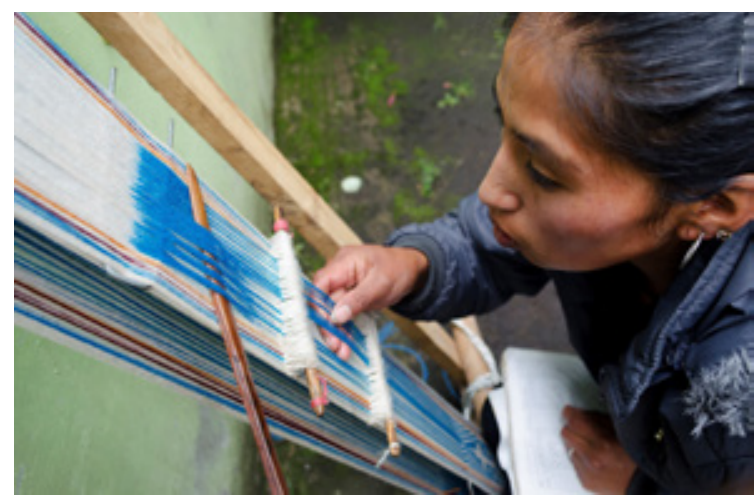

Figura 2. Tejedora de la comunidad de los Pastos Fuente: Fotografía de las autoras. Municipio de Cumbal, Nariño, 2017. 


\section{Metodología}

Enfoque: se utilizó un enfoque cualitativo, que tiene como objetivo describir el contexto y las posibles problemáticas dentro de una cultura, tanto urbana como rural e indígena, puesto que busca comprender comportamientos, sentimientos y gustos tanto de las tejedoras del Municipio de Cumbal como de los jóvenes ciudadanos de Pasto. Cabe resaltar, que para la investigación fue de suma importancia interactuar con la comunidad tejedora, para conocer sus puntos de vista acerca de la problemática planteada y cómo se desenvuelven en su entorno y labores, tales como el tejido.

Método: el método utilizado fue el Crítico-social, ya que buscó el desarrollo comunitario en pro de resolver problemas sociales. Es por esto que, en conjunto con las tejedoras de la comunidad de los Pastos del Municipio de Cumbal, se generaron ideas a partir de su conocimiento acerca del tejido y la simbología de su cultura, para construir una propuesta diferente que llamara la atención de los jóvenes ciudadanos de Pasto.

Tipo: se utilizó un tipo de investigación-acción y participación, como quiera que ésta busca que la comunidad involucrada participe y se apropie del proceso y los resultados. Por tal razón se generaron espacios en los cuales existiera un intercambio de saberes, a partir del diálogo y la interacción con los sujetos, lo que brindó a la investigación bases sólidas para generar, desde diferentes ámbitos, un conocimiento de forma colectiva, con el propósito de resaltar la cultura de los Pastos y lograr un reconocimiento de ésta por parte de jóvenes ciudadanos de Pasto.

Población: tejedoras pertenecientes al Municipio de Cumbal y los jóvenes ciudadanos de Pasto.

Unidad de análisis: tejedoras pertenecientes al Municipio de Cumbal, entre los 25 y 50 años de edad, quienes trabajan la técnica del tejido en guanga y punto crochet. Por otro lado, están jóvenes habitantes de la ciudad de Pasto entre los 18 y 25 años de edad, quienes con su participación brindaron su percepción respecto al diseño de indumentaria.

Para facilitar la creación de soluciones creativas, fue pertinente utilizar una metodología de innovación que brindó herramientas para construir ideas colectivas, en donde los principales actores fueron las comunidades. Es por esto que para la investigación se utilizó como referente la metodología proyectual llamada Feeling, que toma como base el método de trabajo denominado Design Thinking, que consiste en buscar soluciones innovadoras y creativas basadas en las necesidades de las personas. El Design Thinking permitió proponer el reto, detectar las necesidades y darle una solución al problema de manera factible y viable.

Feeling es una metodología para innovar centrada en los sentimientos, deseos y el corazón del Ser Humano. De manera conceptual el proceso de Feeling se inspira en la novela El Principito del escritor y aviador francés Antoine de Saint Exupéry, lo que lleva a comparar los viajes del personaje con las fases mediante las cuales se emprende 
un viaje a través de la innovación. Feeling ayuda a generar procesos de innovación de manera efectiva, combinando el Design Thinking (Pensamiento de diseño), con la creatividad surgida desde las realidades del contexto. (Lohiceconfeeling, 2017, p.xx)

Con lo anterior se puede decir que el proyecto fue soportado en métodos de investigación que son base del diseño centrado en las personas, como lo es el diseño etnográfico, el cual facilitó la interacción con la población dentro de su entorno, para permitir conocer sus comportamientos, acciones, labores, hábitos, entre otros.

Para el desarrollo del proceso, se implementaron las siguientes etapas:

Etapa 1: Acercamiento. El objetivo en esta etapa fue lograr una empatía con las diferentes personas vinculadas con el proyecto; por esto fue clave el trabajo de campo, porque se generó un acercamiento con las comunidades a través de diferentes herramientas que permitieron comprender el comportamiento y pensamiento de cada una de ellas y como resultado lograr empatizar con las comunidades.

Etapa 2: Ideación. Fue importante en esta etapa, sacar a flote la imaginación y la creatividad, para poder crear diversas propuestas que surgieran a través de diferentes ejercicios que hicieran potenciar la imaginación, tanto de los involucrados pertenecientes a la cultura de los Pastos como de jóvenes ciudadanos de Pasto y los diseñadores gráficos que realizaron la investigación.

Etapa 3: Experimentación. Después de explorar con las dos comunidades involucradas, fue importante experimentar con diferentes materiales para hacer tangibles las ideas que hubieran surgido anteriormente, integrando diversas soluciones a partir del tejido, la costura y el diseño gráfico, con el fin de generar una pieza de calidad.

Etapa 4: Prototipado. Gracias a la estructuración de ideas, resultado de la etapa de experimentación, fue posible generar el prototipo real, es decir, las prendas de vestir para jóvenes ciudadanos de Pasto, consolidando así el objetivo de la investigación.

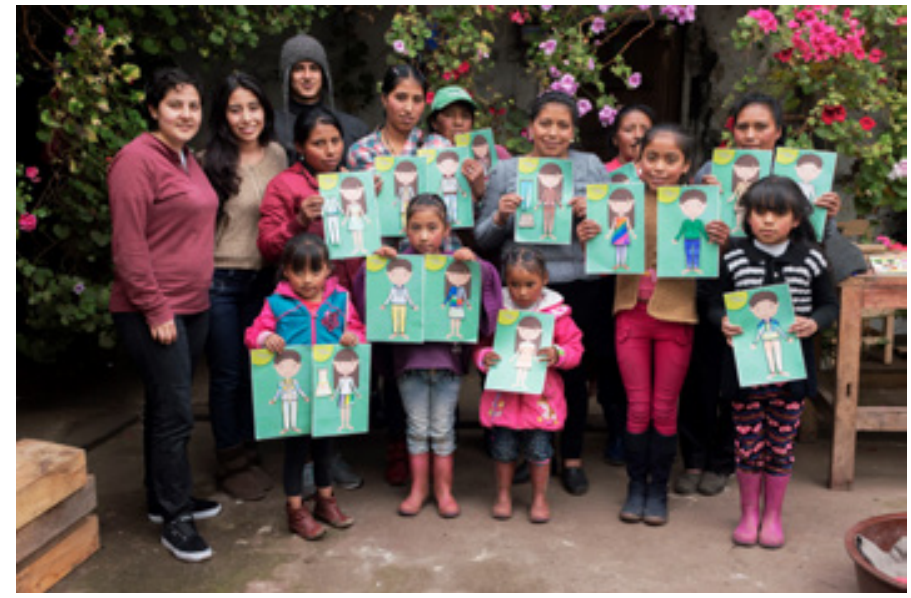

Figura 3. Fase de ideación, comunidad de los Pastos. Fuente: Fotografía de las autoras. Municipio de Cumbal, Nariño, 2017. 


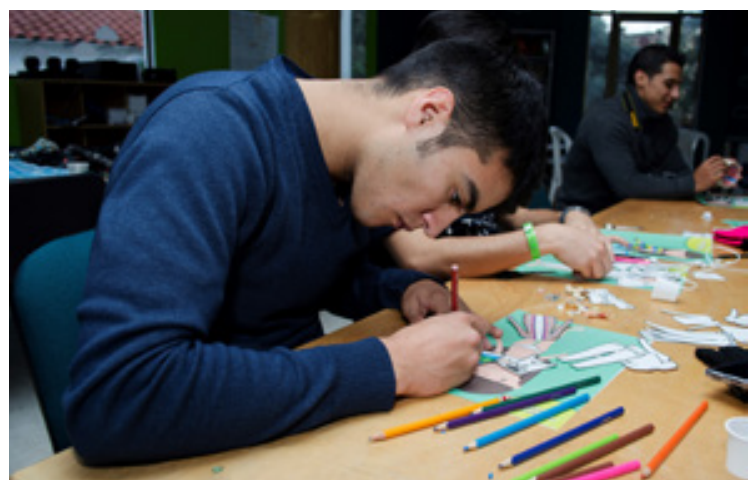

Figura 4. Fase de ideación, jóvenes de la Ciudad de Pasto. Fuente: Fotografía de las autoras. Pasto, Nariño, 2017.

La implementación de estas metodologías y la ejecución de las cuatro fases permitieron alcanzar resultados satisfactorios para las partes; esto se logró gracias a que cada paso fue construido y validado con las comunidades poseedoras del saber ancestral, con los jóvenes de la Ciudad de Pasto que aportaron con su visión sobre indumentaria, y con los investigadores como mediadores en la unificación de dicho conocimiento.

\section{Resultados}

\section{- Línea ancestral}

PAWA salió a la luz de las pasarelas por primera vez, con el lanzamiento de su línea Ancestral, en donde los colores, texturas y símbolos característicos del pueblo indígena de los Pastos, eran los protagonistas. Todos estos elementos propios de una cultura atávica, en conjunto con prendas modernas vestidas por modelos jóvenes, a cada paso contaban historias de un pueblo que por años ha luchado por la reivindicación de sus derechos, que ha buscado siempre rescatar su lengua, tradiciones y creencias.

Los tejidos creados por las manos de mujeres emprendedoras forman hoy parte de prendas modernas que componen esta línea de ropa. En cada hilo se encuentra la historia de un pasado reciente, donde hijos, padres, abuelos lucían estos mismos símbolos en las fajas que los envolvían cuando nacían y durante sus primeros meses de vida, en las ruanas y mantas que los abrazaban para cubrirlos del frío propio de su tierra, que celosamente era vigilada por un nevado; y en cada una de las prendas o accesorios que hacen parte de su cotidianidad y que aún lucen con gran orgullo en ocasiones especiales o simplemente durante la realización de sus tareas diarias en el campo.

De esta manera PAWA, a través de su línea Ancestral, a la vez que reconocía la grandeza y riqueza cultural de un pueblo, le entregaba al mundo una alternativa moderna, cómoda, juvenil y cargada de identidad para que la pudieran lucir, obteniendo las prendas finales que harán parte de esta línea, conformada por un vestido, un pantalón y un chaleco para mujer, un saco y un pantalón jean para hombre. 


\section{Descripción de producto}

\section{- Vestido}

El vestido está elaborado en una tela olán de lino color salmón, tipo veraniego, es decir, está conformado por una falda rizada que forma pliegues a lo largo de la cintura; el busto es ajustado y tiene tirantes delgados tejidos para sostener sobre los hombros; en la parte posterior hay presillas confeccionadas de la misma tela para cruzar un cordón tejido, con el fin de apretar y ceñir el vestido al cuerpo. Por último, en la parte del talle se incrustó el tejido para formar la cintura de la modelo.

El aplique en tejido fue realizado en la técnica de punto crochet; lleva color azul, morado, magenta y crema; su diseño cuenta con churos cósmicos que representan el principio de la vida, el tiempo infinito, el agua y la fertilidad; las escaleras que simbolizan la subida al cielo, los puntos que aluden a los grupos que se asentaban en el territorio y el Sol de los Pastos como divinidad solar que la cultura adoraba.

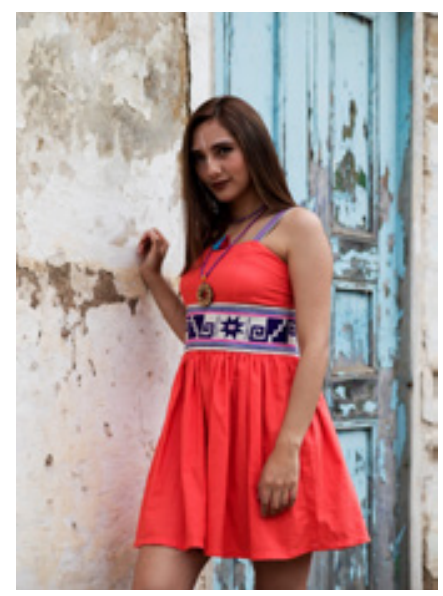

Figura 5. Vestido para mujer.

Fuente: Fotografía de las autoras. Corregimiento de Cabrera, Municipio de Pasto, 2017.

\section{Pantalón para mujer}

Para la confección de esta prenda se utilizó tela crepe de color azul marino, la cual permite generar prendas cómodas por su holgura, ofreciendo libertad de movimiento. Es por esto que el diseño de este pantalón es tipo bombacho, que se caracteriza por ser ancho y suelto, pero también por ajustarse con el tejido en la cintura y tobillos, con el fin de ceñir el cuerpo y las piernas, respectivamente.

El aplique en tejido fue realizado con la técnica en guanga, lleva colores como amarillo, crema, magenta, verde y morado; en su diseño se encuentra el churo cósmico que representa la forma circular de los grupos que se asentaban en el territorio, figuras geométricas como triángulos que hacen alusión a la naturaleza, los puntos que simbolizan a los ancestros y las varas de mando que representan el poder. 


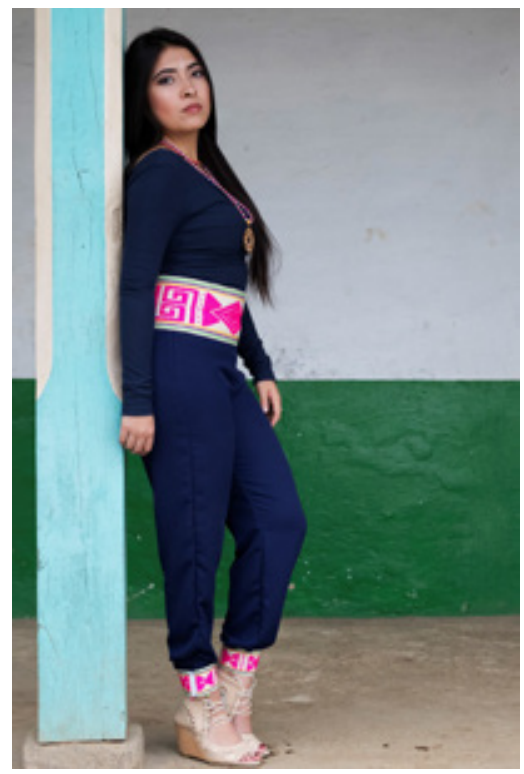

Figura 6. Pantalón para

mujer

Fuente: Fotografía de las autoras. Corregimiento de Cabrera, Municipio de Pasto, 2017.

\section{Saco}

Para la confección del saco se utilizó una tela llamada circuito franela, caracterizada por su suavidad, elasticidad y durabilidad. Por esta razón permite formar una prenda fresca con un corte estilo cárdigan para hombre, en el cual se aplicó el tejido a lo largo del cuello y talle. El tejido incrustado en esta prenda se elaboró con la técnica en guanga, lleva colores como amarillo, crema, vinotinto y azul; su diseño cuenta con los helechos en representación del entorno y la naturaleza, líneas que representan las tierras y variedad de cultivos, la Chacana que simboliza la conexión entre el cielo y la tierra, entre el hombre y lo superior; y, por último, el churo cósmico que alude al principio de la vida, del tiempo infinito, el agua y la fertilidad.

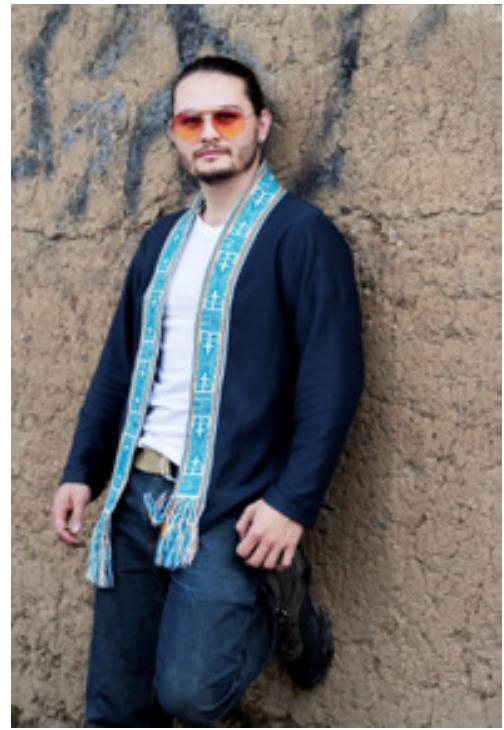

Figura 7. Saco para hombre

Fuente: Fotografía de las autoras. Corregimiento de Cabrera, Municipio de Pasto, 2017. 


\section{- Chaleco}

El chaleco de jean fue seleccionado para ser parte de esta línea de ropa, por cuanto representa un estilo casual y juvenil. En él se realizaron incrustes remplazando partes de éste con tejido en las tapas y debajo de los bolsillos, en la cotilla de la espalda y también se colocaron presillas en los hombros y en la parte inferior del chaleco.

Los tejidos aplicados aquí fueron elaborados en punto crochet, llevan colores como magenta, azul, verde y crema; el diseño contiene perdices que representan la dualidad, el día y la noche, hombre y mujer; también se encuentran líneas que aluden a los caminos por los que transitaban los ancestros y los Cusillos o monos que son considerados como ancestros sagrados.

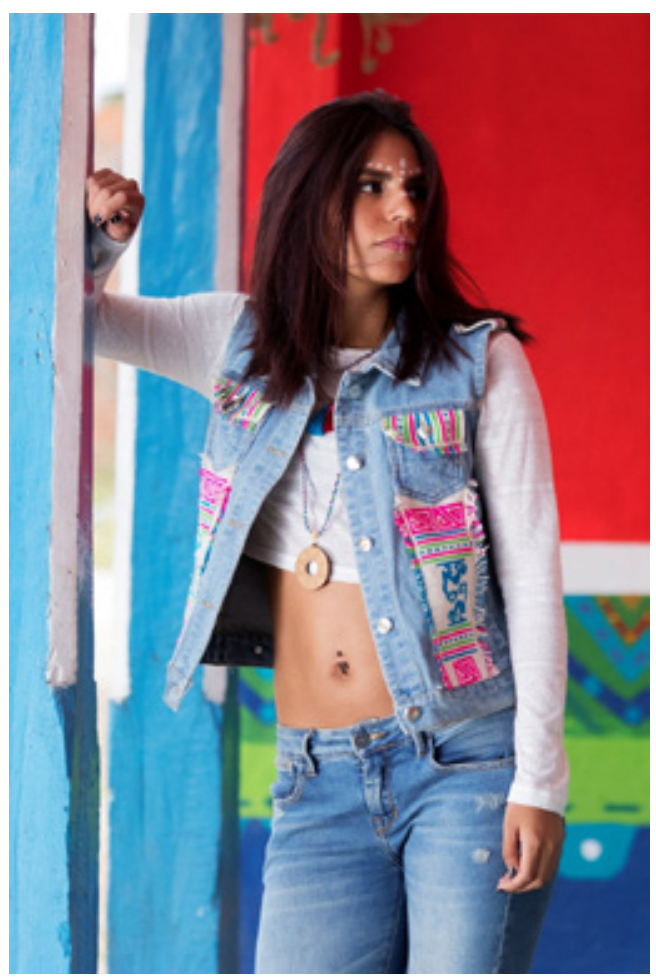

Figura 8. Chaleco jean para mujer.

Fuente: Fotografía de las autoras. Corregimiento de Cabrera, Municipio de Pasto, 2017.

\section{- Pantalón Jean}

En el pantalón jean de color azul índigo de estilo Slim-Straight, se remplazaron las presillas por tiras tejidas, también se colocó un fajón como cinturón para exhibir el diseño (remplazando a los cinturones comunes) e, igualmente, se aplicó el tejido en los puños del pantalón dándole forma a la bota. Los tejidos fueron elaborados en guanga y llevan colores como amarillo, naranja, café y crema, su diseño cuenta con las perdices que representan la dualidad, el día y la noche, al hombre y a la mujer, también líneas que representan los caminos por los que transitaban los ancestros y las tierras que cosechaban. 


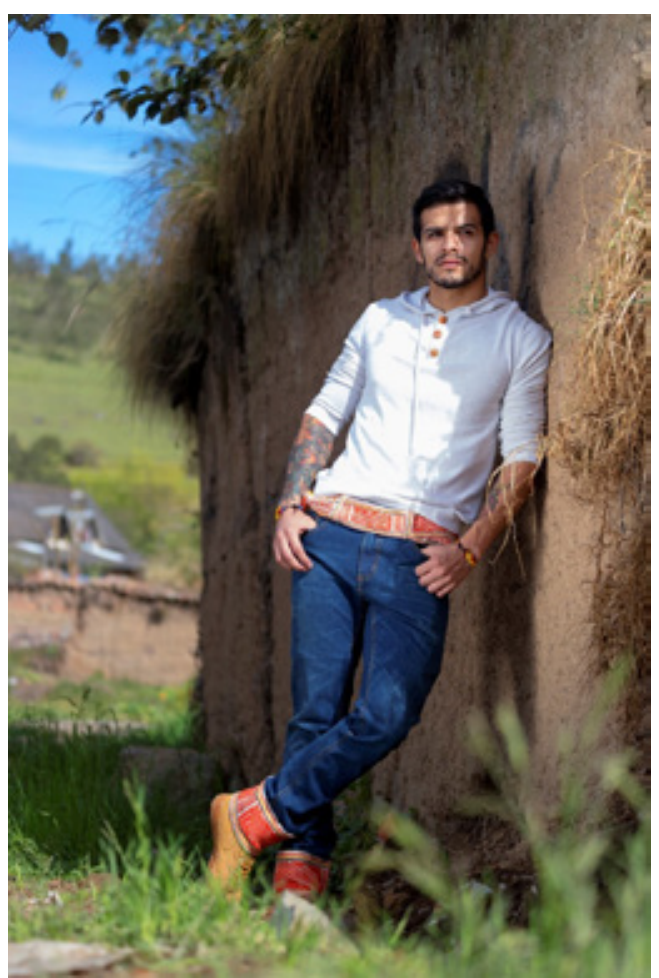

Figura 9. Pantalón jean para hombre.

Fuente: Fotografía de las autoras. Corregimiento de Cabrera, Municipio de Pasto, 2017.

\section{Sobre PAWA}

PAWA nació con el propósito de resaltar la cultura nariñense del pueblo indígena de los Pastos, quienes, a través de símbolos, texturas y colores, plasmados por sus mujeres en tejidos elaborados en guanga y punto crochet, fusionados con prendas llamativas y contemporáneas para jóvenes, ponen al descubierto su tradición y le entregan al mundo de la moda una nueva alternativa de vestir y perpetuar un legado. PAWA es la contracción de las palabras Pai Warmi, que significa Gracias Mujer, un homenaje a la mujer y al trabajo que desarrollan las tejedoras del Municipio de Cumbal.

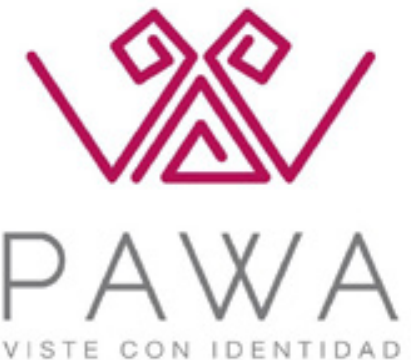




\section{Conclusiones}

PAWA ofrece al cliente una prenda exclusiva que representa la Cultura de los Pastos, su simbología, colores y texturas, a través de una técnica ancestral como el tejido artesanal, realizado por las manos creadoras de la mujer indígena.

El objetivo principal de PAWA es resaltar el trabajo de las tejedoras de Cumbal, Nariño, para quienes el tejer se convierte en una forma de asumir la cotidianidad, de la rutina propia de los campos. Aquí es donde canalizan sus emociones, tejen sus sueños y entrelazan los hilos de su vida.

El trabajo se torna valioso, porque cada tejido es elaborado con sus propias manos, le han depositado su tiempo, esfuerzo y dedicación, pues el tejer no es algo sencillo, requiere de varios procesos, necesita de mucha imaginación, creatividad y paciencia para darle vida a cada diseño.

Gracias al trabajo de investigación fue posible evidenciar que, lastimosamente, el arte de tejer es un oficio poco valorado y, por lo tanto, se ha ido perdiendo poco a poco. Es por esto que PAWA se convierte en una alternativa para resaltar la cultura de los Pastos y la técnica del tejido, fusionándola con otras como la alta costura y distintos materiales, con el objetivo de reivindicar el trabajo de las mujeres tejedoras de Cumbal, generando productos de indumentaria diferentes y dando a conocer el trabajo y las habilidades que ellas poseen.

Al llevar esta propuesta al mercado, específicamente a los jóvenes de Pasto, se dio el primer paso para que la cultura ancestral del pueblo de los Pastos continúe escribiendo su historia. 


\section{Referencias}

Alcaldía del Municipio de Pasto. (2011). Pasto, ciudad sorpresa de Colombia. (3 $3^{a}$ ed.). San Juan de Pasto: Alcaldía de Pasto.

Alcaldía del Municipio de Cumbal. (2009). Esquema de ordenamiento territorial del municipio de Cumbal. Cumbal, Nariño: Alcaldía Municipal de Cumbal.

Chirán Caipe, R.A. \& Burbano Hernández, M. (enero, 2013). La dualidad andina del pueblo Pasto, principio filosófico ancestral inmerso en el tejido en guanga y la espiritualidad. Plumilla Educativa, 11(1), 136-156.

Feeling: La Memoria Urbana. (2013). Metodología para innovar inspirada en "El Principito". Recuperado de https://lamemoriaurbana.wordpress.com/2013/08/15/feelingmetodologia-para-innovar-inspirada-en-el-principito/

Las cinco fases del Design Thinking. (2017). INHISET. Recuperado de https://www.inhiset. com/noticias/109-las-5-fases-del-desing-thinking

Pantoja Medina, A.S. (2009). El color del tejido en el Nudo de los Pastos; Asociación “Piedra de Machines" Resguardo Indígena del Gran Cumbal (Tesis de Licenciatura). Universidad de Nariño, San Juan de Pasto.

Tavera de Téllez, G. \& Urbina Caicedo, C. (1994). Textiles de las culturas Muisca y Guane. Quito: IADAP, Universidad de los Andes.

Uribe, Z. M. (2004). Introducción a la Semiótica del Diseño Andino Precolombino. Lima: Amaru Wayra. 